INTERNACIONAL

\title{
Derechos humanos y medioambiente: La situación de los defensores ambientales en América Latina, y los obstáculos legales e institucionales para su actuar
}

\author{
Human rights and environment: The situation of environmental human rights \\ defenders in Latin America, and the legal and institutional obstacles in their work
}

\author{
María Francisca Aguilar Campos \\ Universidad de Chile
}

\begin{abstract}
RESUMEN Durante las últimas décadas en América Latina, el derecho a vivir en un medio ambiente sano se ha ido desarrollando y cobrando importancia, hasta que su innegable vínculo con los derechos humanos ha sido reconocido por parte de la comunidad internacional; ello será abordado en la primera y segunda parte del artículo. En este contexto, los recursos naturales, los derechos de las comunidades y los proyectos de inversión que buscan explotar dichos recursos convergen en situaciones usualmente no pacíficas. Frente a ello, defensores ambientales se interponen con el objeto de promover y proteger los derechos humanos en juego, con especial foco en el ambiente e identidad cultural afectada. Sin embargo, a menudo son objeto de amenazas e incluso violencia física y muerte. Aunque las declaraciones internacionales respaldan los derechos de los defensores del medio ambiente, las leyes domésticas a menudo socavan estas protecciones; en la tercera parte del artículo, se precisarán estos aspectos y los casos de dificultades institucionales y legales que tienen que enfrentar en la región. Finalmente, se presentan algunas buenas prácticas en la región para la protección de los defensores ambientales hacia las que se estima necesario apuntar.
\end{abstract}

PALABRAS CLAVE Derechos humanos, medio ambiente, defensores de derechos humanos, defensores ambientales, Acuerdo de Escazú.

ABSTRACT In recent decades in Latin America, the right to live in a healthy environment has been developing and gaining importance, to the point that its undeniable link with human rights has been recognized by the international community; this will be addressed in the first and second parts of the article. In this context, the rights of the communities and the investment projects that seek to exploit natural resource-rich areas usually converge in non-peaceful situations. Faced with these challenges, environmental 


\begin{abstract}
defenders promote and protect the human rights, with special focus on the environment and affected cultural identity. However, they are often subjected to threats and even physical violence and death. Although international declarations support the rights of environmental defenders, domestic laws often undermine these protections; the third part of the article will specify these aspects and the cases of institutional and legal difficulties that they face in the region. Finally, some good practices are presented in the region for the protection of environmental defenders.
\end{abstract}

KEYWORDS Human rights, environment, human rights defenders, environmental defenders, Escazú Agreement.

\title{
Medio ambiente sano y derechos humanos
}

El objetivo del presente artículo es evidenciar la situación de los defensores ambientales en América Latina y el Caribe, para determinar quiénes son y cuál es su regulación internacional, así como las barreras legales que minan su labor y las buenas prácticas regionales que actúan en su favor. Sin perjuicio de ello, un estudio serio de los defensores ambientales hace ineludible analizar el vínculo de un medio ambiente sano con los derechos humanos.

Para abordar la pregunta de si el derecho a un medio ambiente sano puede consi-

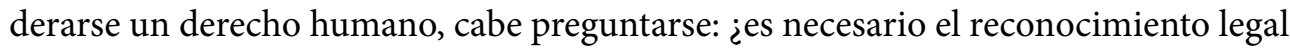
formal en un documento internacional (hard o soft law) para que tenga el estatus de un derecho humano? ¿Es el derecho a un medio ambiente sano un derecho autónomo, o viene en la protección de otros derechos civiles, políticos, económicos, sociales y culturales?

Como ha señalado Rodríguez-Garavito (2018), los derechos humanos deben entenderse como «demandas morales», en lugar de demandas legales. Así las cosas, «los derechos son afirmaciones fundamentalmente morales sobre el valor intrínseco de cada ser humano y sobre la importancia de las prerrogativas que protegen para una vida humana digna» (Rodríguez-Garavito, 2018: 156-157). De esta forma, los derechos humanos deben ser tomados en cuenta desde un punto de vista ético, lo cual afirma su importancia ética intrínseca.

En este orden de ideas, invocar el derecho a un medio ambiente sano implica una fuerte afirmación ética sobre la importancia de un ambiente natural habitable para una existencia humana digna. Así, además de su papel esencial en el disfrute de otros derechos humanos (civiles, políticos, económicos, sociales y culturales), tiene un significado ético intrínseco. Ello, porque protege específicamente las condiciones básicas de la existencia individual y comunitaria que se ven amenazadas debido al creciente estrés ecológico. Dichas condiciones se pueden evidenciar en la relación 
de los seres humanos con su entorno viviente, la posibilidad de permanecer en su hábitat y desarrollar una relación sostenible con la naturaleza, los derechos de las generaciones futuras para disfrutar de un planeta habitable, e incluso el reconocimiento potencial de ciertos derechos a animales no humanos y entidades naturales (Rodríguez-Garavito, 2018: 157).

Así las cosas, desde una perspectiva moral y sin la necesidad de basar un derecho en la ley, se puede establecer que el derecho al medio ambiente sano ya es un derecho humano, y un derecho autónomo de otros derechos civiles, políticos, sociales y culturales.

Esta idea se refuerza en la práctica, pues es frecuente que personas, tribunales e incluso los Estados hagan demandas basadas en los derechos con anterioridad a que el derecho respectivo haya sido reconocido en un documento legal formal (RodríguezGaravito, 2018: 158). Así, por ejemplo, la Declaración de las Naciones Unidas sobre los Derechos de los Pueblos Indígenas de 2007 demoró más de veinte años en ser adoptada; aun así, durante ese intertanto los movimientos de los pueblos indígenas utilizaron el lenguaje de los derechos humanos con eficacia. De manera similar, desde la Declaración de Estocolmo de 1972 de la Conferencia de las Naciones Unidas sobre el Medio Humano, la sociedad civil y los actores estatales han estado invocando el derecho a un medio ambiente saludable con independencia del hecho de que no se ha incorporado formalmente en un instrumento jurídico internacional (RodríguezGaravito, 2018: 158).

Asimismo, y como se verá a continuación, numerosas constituciones políticas en el mundo, y en particular en América Latina y el Caribe, han incorporado el derecho a un medio ambiente sano a la legislación nacional. Por su parte, el ambiente sano ha alcanzado amplio desarrollo legislativo en cada Estado, lo que incluye políticas públicas e incluso litigios.

Con todo, lograr un marco legal explícito del medio ambiente sano como derecho humano es beneficioso por las razones que se detallarán en el capítulo siguiente. Ahora bien, si el esfuerzo por formalizarlo en un instrumento de derecho internacional se viera frustrado, y a la luz de las razones ya revisadas, ello no restará valor a su condición como derecho humano, ni a la capacidad de diversos actores para invocarlo como tal.

Cabe resaltar, por último, que el derecho en cuestión incluso tiene una base práctica más sólida de lo que su estado moral por sí solo justifica. De hecho, se basa en el derecho constitucional comparado y la práctica internacional, como se detalla a continuación, hasta el punto de alcanzar, en opinión de Rodríguez-Garavito (2018), el estado de derecho internacional consuetudinario. 


\section{Evolución del derecho a vivir en un medio sano como derecho constitucional en los países de la región, y su entendimiento en el ámbito internacional como un derecho humano}

\section{Medio ambiente y las constituciones en América Latina y el Caribe}

A partir de los años setenta, las constituciones de América Latina y el Caribe han experimentado sucesivos cambios y, en particular, han recogido en sus respectivos textos la preocupación por la protección ambiental.

Ello cobra sentido a la luz de la Conferencia de las Naciones Unidas sobre el Medio Humano en 1972, en la cual se puso de manifiesto el interés en la relación entre derechos humanos y medio ambiente. Dicho interés se relacionaba con dos temas clave: cuál es la naturaleza de la relación entre los derechos humanos y el medio ambiente, y si la comunidad internacional debería reconocer un nuevo derecho humano, esto es, el derecho a un medio ambiente sano (Cepal y Naciones Unidas, 2018: 27).

Luego, con la Conferencia de las Naciones Unidas sobre el Medio Ambiente y el Desarrollo, en 1992, América Latina y el Caribe dio un importante impulso para la protección ambiental, lo que propició la creación de legislación e institucionalidad ambiental y la construcción de los primeros instrumentos de gestión ambiental.

Ahora bien, se puede señalar que los principales cambios constitucionales en la región, que muestran una evolución a nivel constitucional, son el deber del Estado de proteger el medio ambiente y el derecho a un medio ambiente sano ${ }^{1}$ (o equivalente, como libre de contaminación, ${ }^{2}$ equilibrado, ${ }^{3}$ saludable). ${ }^{4}$ Aunque en el caso de Cuba, El Salvador, Guatemala y Guyana sus respectivas constituciones no establecen el derecho a un ambiente sano, sí incluyen el deber de protección del Estado sobre éste y los recursos naturales. ${ }^{5}$ Haití, por su parte, incluye la prohibición estricta de cualquier práctica que pueda perturbar el ambiente por considerarlo el marco natural de vida para las personas. ${ }^{6}$ Por último, Uruguay establece que la protección del medio ambiente es de interés general, por lo que las personas deben abstenerse de cualquier

1. Constitución de Argentina (1994), artículo 41; Constitución de Bolivia (2009), artículo 30.2 número 10 y artículo 33; Constitución de Colombia (1991), artículo 79; Constitución de Costa Rica (1949), artículo 50; Constitución de Ecuador (2008), artículo 14; Constitución de México (1917), artículo 4; Constitución de Panamá (1972), artículo 118; Constitución de República Dominicana (2010), artículo 67 número 1.

2. Constitución de Chile (1980), artículo 19 número 8.

3. Constitución de Brasil (1988), artículo 225; Constitución de Perú (1993), artículo 2 número 22.

4. Constitución de Jamaica (1962), artículo 13, número 3, letra 1); Constitución de Nicaragua (1986), artículo 60; Constitución de Paraguay (1992), artículo 7.

5. Constitución de Guyana (1980), artículo 36; Constitución de de Cuba (1976), artículo 27; Constitución de El Salvador (1983), artículo 117.

6. Constitución de Haití (1987), artículo 253. 
acto que cause depredación, destrucción o contaminación graves al medio ambiente. ${ }^{7}$ La distinción entre las distintas fórmulas empleadas en uno y otro caso no es superficial, pues determina el rango de acción que tendrán las personas para hacer efectivo el disfrute a un ambiente sano. En este sentido, ha existido discusión respecto de la garantía de un ambiente sano frente a un ambiente libre de contaminación. ${ }^{8}$

En este orden de ideas, el «Informe del relator especial sobre la cuestión de las obligaciones de derechos humanos relacionadas con el disfrute de un medio ambiente sin riesgos, limpio, saludable y sostenible» develó el inusual desarrollo de las normas de derechos humanos en relación con el medio ambiente, pues a nivel mundial persiste el hecho de que tales normas no se basan primordialmente en el reconocimiento expreso de un derecho humano a un medio ambiente saludable. Aunque el derecho a un ambiente sano ha sido reconocido de diversas formas en la mayoría de las constituciones de la región - como ya se revisó- e incluso por la comunidad internacional —como se verá más adelante-, aún no se ha plasmado en el contexto de un acuerdo de derechos humanos de aplicación mundial.

Con todo, el informe del relator especial destaca, sobre la base de la experiencia de los países que han establecido derechos constitucionales a un medio ambiente saludable, que el reconocimiento de ese derecho ha demostrado tener ventajas reales: ha aumentado la visibilidad y la importancia de la protección ambiental y ha servido de base para la promulgación de leyes ambientales más sólidas; $y$, cuando ha sido aplicado por los tribunales, ha contribuido a establecer una red para proteger contra las lagunas en la legislación, lo que ha generado oportunidades para mejorar el acceso a la justicia. Quizás lo más importante es que la evidencia empírica también indica que «los derechos ambientales contribuyen a un desempeño ambiental más fuerte, incluyendo aire más limpio, agua potable más segura y huellas ecológicas más pequeñas» (Boyd, 2018: 26).

A partir de esa experiencia, el relator especial recomendó al Consejo de Derechos Humanos de Naciones Unidas considerar la posibilidad de apoyar el reconocimiento de ese derecho en un instrumento mundial. En este sentido, cabe destacar la iniciativa por el Pacto Mundial por el Medio Ambiente (Resolución 72/277.e4, de 2018), el cual está llamado a ser el marco general normativo de una nueva generación de derechos humanos o de «derecho ambiental internacional». Es así que el nuevo relator especial en derechos humanos y medio ambiente, David R. Boyd, también ha compartido la creciente urgencia de abordar un medio ambiente sano como un derecho humano, ${ }^{9}$ en un contexto geológico marcado por el acelerado impacto del ser

7. Constitución de Uruguay (1967), artículo 47.

8. Sobre este tema, se recomienda revisar Aguilar Cavallo (2016).

9. «Environmental hazards kill 8 million a year: UN expert urges global recognition of the human right to a healthy environment», Oficina del Alto Comisionado para los Derechos Humanos, 25 de octubre de 2018, disponible en https://bit.ly/3faG8FX. 
humano en el planeta, y en un escenario climático que propende en forma sostenida al alza de la temperatura global.

Medio ambiente y derechos humanos, la relación virtuosa reconocida por la comunidad internacional

Como se revisó en el primer apartado, significativos avances se han hecho en el ámbito internacional para clarificar la relación entre derechos humanos y medio ambiente. En una primera etapa, instrumentos como la Declaración Universal de Derechos Humanos de 1948 - y su par americana del mismo año, la Declaración Americana de Derechos y Deberes del Hombre-, el Pacto Internacional de los Derechos Civiles y Políticos (PIDCP) de 1966, y el Pacto Internacional para los Derechos Sociales, Económicos y Culturales (PIDESC) de 1966, incorporaron los primeros elementos para relacionar el ambiente con el disfrute de los derechos humanos, aunque no como un derecho independiente, sino asociado al disfrute de otros derechos. Destacan en este sentido las nociones del uso de los recursos naturales de cada nación (PIDCP, artículo 1; PIDESC, artículos 1 y 25), el derecho de toda persona a un nivel de vida adecuado para sí y su familia y a una mejora continua de las condiciones de existencia (PIDESC, artículos 7 y 11; Declaración Universal de Derechos Humanos, artículo 25), el derecho de toda persona al disfrute del más alto nivel posible de salud física y mental tomando como una medida el mejoramiento en todos sus aspectos de la higiene del trabajo y del medio ambiente (PIDESC, artículo 12).

En el ámbito propiamente regional, se encuentra la Convención Americana de Derechos Humanos (CADH) de 1969, la cual consagra principios y derechos de libertad, igualdad y justicia social que son intrínsecos a la democracia, y establece dos órganos: la Comisión Interamericana de Derechos Humanos (CIDH) y la Corte Interamericana de Derechos Humanos (Corte IDH), que cumplen roles preponderantes en la región en la determinación del ambiente sano y derechos humanos.

Ahora bien, son otros instrumentos de carácter más específico los que definen la relación entre estos dos elementos.

En la Conferencia de las Naciones Unidas sobre el Medio Ambiente y el Desarrollo, celebrada en Río de Janeiro en 1992, casi todas las naciones aceptaron sin reservas el Principio 1 de la Declaración de Río, el cual dispone que «los seres humanos constituyen el centro de las preocupaciones relacionadas con el desarrollo sostenible. Tienen derecho a una vida saludable y productiva en armonía con la naturaleza».

Aunque este principio no se refiere explícitamente al derecho a un medio ambiente saludable, su lenguaje es consistente con la teoría moral de los derechos humanos analizada. Los términos del Principio 1 se han reafirmado en varias declaraciones internacionales, como las resultantes de la Conferencia de las Naciones Unidas sobre Población y Desarrollo de 1994, la Cumbre Mundial sobre Desarrollo Social de 1995 y la 
Segunda Conferencia sobre Asentamientos Humanos de 1996. De esta forma, si bien ninguna de estas reafirmaciones es legalmente vinculante, el hecho de que casi todas las naciones hayan hecho esta reafirmación sin reservas, al menos tres veces, es evidencia de una práctica estatal generalizada y consistente (Rodríguez-Garavito, 2018: 161).

A su vez, el derecho a un medio ambiente sano ha logrado reconocimiento en cuatro tratados vinculantes. Primero, el artículo 24 de la Carta Africana, también conocida como la Carta de Banjul, establece: «Todos los pueblos tendrán derecho a un entorno general satisfactorio favorable a su desarrollo». En segundo lugar, el artículo 38 de la Carta Árabe de Derechos Humanos reconoce que «toda persona tiene derecho a [...] un ambiente saludable». En tercer lugar, en Europa, el derecho se reconoce en la Convención de Aarhus, a través del artículo 1, el cual señala: «A fin de contribuir a proteger el derecho de cada persona, de las generaciones presentes y futuras, a vivir en un medio ambiente que permita garantizar su salud y su bienestar, cada parte garantizará los derechos de acceso». En cuarto lugar, y especialmente relevante para la región, aunque de naturaleza adicional a la $\mathrm{CADH}$, se encuentra el Protocolo de San Salvador, el cual en su artículo 11 dispone: «Toda persona tiene derecho a vivir en un medio ambiente sano y a contar con servicios públicos básicos» (artículo 11, números 1 y 2). No se puede dejar de mencionar en el ámbito regional el Acuerdo de Escazú, que si bien aún no entra en vigor, dispone en su artículo 1:

El objetivo del presente Acuerdo es garantizar la implementación plena y efectiva en América Latina y el Caribe de los derechos de acceso a la información ambiental, participación pública en los procesos de toma de decisiones ambientales y acceso a la justicia en asuntos ambientales, así como la creación y el fortalecimiento de las capacidades y la cooperación, contribuyendo a la protección del derecho de cada persona, de las generaciones presentes y futuras, a vivir en un medio ambiente sano $\mathrm{y}$ al desarrollo sostenible.

Así las cosas, desde una perspectiva legal, el derecho a un ambiente sano calificaría como parte del derecho internacional vinculante, bajo una comprensión contemporánea del derecho internacional consuetudinario. El reconocimiento del derecho en la mayoría de las constituciones y cuatro instrumentos regionales de derechos humanos, junto con numerosos instrumentos internacionales, ofrece evidencia sólida tanto de la práctica estatal relevante como de la opino juris necesaria para otorgar al derecho el estatus de derecho internacional consuetudinario (Rodríguez-Garavito, 2018: 159).

Vale la pena destacar los enormes avances que ha logrado la Corte IDH en establecer el vínculo de un ambiente sano y los derechos humanos. Así, el 15 de noviembre de 2017, la Corte IDH dictó la Opinión Consultiva OC-23/17, ${ }^{10}$ en respuesta a la

10. Opinión Consultiva OC-23/17 sobre Medio Ambiente y Derechos Humanos, «Obligaciones esta- 
consulta por el Estado de Colombia sobre las obligaciones estatales en relación con el medio ambiente, en el marco de la protección y garantía de los derechos a la vida y a la integridad personal. En concreto, sobre el derecho humano a un medio ambiente sano, estableció que

el derecho humano a un medio ambiente sano se ha entendido como un derecho con connotaciones tanto individuales como colectivas. En su dimensión colectiva, el derecho a un medio ambiente sano constituye un interés universal, que se debe tanto a las generaciones presentes y futuras. Ahora bien, el derecho al medio ambiente sano también tiene una dimensión individual, en la medida en que su vulneración puede tener repercusiones directas o indirectas sobre las personas debido a su conexidad con otros derechos, tales como el derecho a la salud, la integridad personal o la vida, entre otros. La degradación del medio ambiente puede causar daños irreparables en los seres humanos, por lo cual un medio ambiente sano es un derecho fundamental para la existencia de la humanidad (párrafo 59).

Asimismo, se refiere a éste como derecho autónomo cuando dice que el

derecho al medio ambiente sano como derecho autónomo, a diferencia de otros derechos, protege los componentes del medio ambiente, tales como bosques, ríos, mares y otros, como intereses jurídicos en sí mismos, aun en ausencia de certeza o evidencia sobre el riesgo a las personas individuales. Se trata de proteger la naturaleza y el medio ambiente no solamente por su conexidad con una utilidad para el ser humano o por los efectos que su degradación podría causar en otros derechos de las personas, como la salud, la vida o la integridad personal, sino por su importancia para los demás organismos vivos con quienes se comparte el planeta, también merecedores de protección en sí mismos (párrafo 59).

En este mismo sentido, la Corte IDH dictó el 6 febrero de 2020 una nueva sentencia relacionada con la demarcación, titulación y saneamiento del territorio tradicional de varias comunidades indígenas en el norte de Argentina (Lhaka Honhat). ${ }^{11}$ Desde hace varias décadas, estas comunidades reivindican la propiedad sobre su territorio ancestral y demandan la emisión de un título común e indiviso, con el fin de preservar sus modos de vida y prácticas culturales.

Lhaka Honhat es el primer caso contencioso en el que la Corte IDH debe pronun-

\footnotetext{
tales en relación con el medio ambiente en el marco de la protección y garantía de los derechos a la vida y a la integridad personal: Interpretación y alcance de los artículos 4.1 y 5.1, en relación con los artículos 1.1 y 2 de la Convención Americana sobre Derechos Humanos», Corte Interamericana de Derechos Humanos.

11. Sentencia del caso Comunidades indígenas miembros de la Asociación Lhaka Honhat (Nuestra Tierra) con Argentina, Corte Interamericana de Derechos Humanos, serie C núm. 40o, fondo, reparaciones y costas, 6 de febrero de 2020 .
} 
ciarse sobre los derechos a un medio ambiente sano, a la alimentación adecuada, al agua y a participar en la vida cultural a partir del artículo 26 de la CADH.

En este fallo, la Corte IDH reitera el argumento establecido en la Opinión Consultiva OC-23/17, al declarar que «el derecho a un medio ambiente sano debe considerarse incluido entre los derechos [...] protegidos por el artículo 26 de la Convención Americana, dada la obligación de los Estados de alcanzar el desarrollo integral de sus pueblos, que surge de los artículos 30, 31, 33 y 34 de la Carta». ${ }^{12}$

La sentencia, por una parte, refuerza la potestad de la Corte IDH para crear nuevos derechos sin un correlato en las normas de la Carta de la OEA o en la Declaración Americana sobre los Derechos y Deberes del Hombre; por otra, establece el reconocimiento de nuevos derechos autónomos por vía interpretativa.

\section{Dificultades institucionales y legales que tienen que enfrentar los defensores en la región}

\section{Quiénes son los defensores ambientales y su regulación internacional}

La Declaración sobre el Derecho y el Deber de los Individuos, los Grupos y las Instituciones de Promover y Proteger los Derechos Humanos y las Libertades Fundamentales Universalmente Reconocidos (en adelante como Declaración sobre Defensores) define a los defensores como cualquier persona que trabaja por la promoción y la protección de los derechos humanos de manera pacífica (A/RES/53/144, Naciones Unidas, 1999). Asimismo, la Corte IDH ha considerado que la calidad de defensor radica en la tarea que cumple, con independencia de que la persona sea un particular o un funcionario público, ${ }^{13} \mathrm{y}$ ha destacado su labor considerándola «fundamental para el fortalecimiento de la democracia y el Estado de derecho». ${ }^{14}$ Dichas actividades de promoción y protección de los derechos humanos pueden ejercerse en forma intermitente $\mathrm{u}$ ocasional, por lo que la calidad de defensores de derechos humanos no constituye por necesidad una condición permanente, ni es condición que reciba un pago por sus labores o pertenezca a una organización civil. ${ }^{15}$

12. Comunidades indígenas miembros de la Asociación Lhaka Honhat (Nuestra Tierra) con Argentina, párrafo 202.

13. Sentencia del caso Luna López con Honduras, Corte Interamericana de Derechos Humanos, serie C núm. 269, fondo, reparaciones y costas, 10 de octubre de 2013, párrafo 122.

14. Sentencia del caso Valle Jaramillo y otros con Colombia, Corte Interamericana de Derechos Humanos, serie C núm. 192, fondo, reparaciones y costas, 27 de noviembre de 2008, párrafo 87.; y sentencia del caso Castillo González y otros con Venezuela, Corte Interamericana de Derechos Humanos, serie C núm. 256, fondo, 27 de noviembre de 2012, párrafo 124.

15. «Segundo informe sobre la situación de las defensoras y defensores de derechos humanos en las Américas», Comisión Interamericana de Derechos Humanos, OEA/Ser.L/V/II, 31 de diciembre de 2011, disponible en https://bit.ly/32otNQK. 
En este contexto, los defensores ambientales son quienes trabajan no solo para la protección de los derechos civiles, políticos, económicos, sociales y culturales, sino además para la protección de los diversos componentes ambientales (agua, aire, biodiversidad, etcétera), territorio y medio ambiente. En muchas ocasiones, defensores son también miembros y líderes de comunidades indígenas y afrodescendientes, o pueden ser integrantes de movimientos de otros derechos humanos. En gran medida, dichos defensores están enfocados en exigir el respeto de los derechos a la tierra y a los componentes ambientales de las comunidades afectadas por proyectos o actividades de inversión, así como el cumplimiento efectivo del derecho a la consulta previa y consentimiento libre, previo e informado para el uso y explotación de su territorio (ISHR, 2015).

En este orden de ideas, Susana Borras (2019) señala que los defensores ambientales sufren la violación de sus derechos más fundamentales como consecuencia de una degradación ambiental previa. La mayoría de los casos, por lo tanto, están relacionados con la degradación ambiental del hábitat de comunidades indígenas o pobres. Estos defensores del medio ambiente no siempre corresponden a «activistas» o a miembros de organizaciones en defensa del medio ambiente, sino que con frecuencia son personas que simplemente se enfrentan a decisiones importantes que afectan su medio ambiente, o pueblos indígenas cuyo uso tradicional de sus tierras es amenazado.

Por su parte, la ONG Global Witness define a estas personas como

alguien que toma medidas pacíficas, voluntaria o profesionalmente, para proteger los derechos ambientales o de la tierra. A menudo son personas ordinarias que bien pueden no definirse como «personas defensoras». Algunas son líderes indígenas o campesinas que viven en montañas remotas o bosques aislados, que protegen sus tierras ancestrales y sus medios de vida tradicionales de proyectos mineros, agronegocios a gran escala, represas hidroeléctricas y hoteles de lujo. Otros son guardaparques, que abordan la caza furtiva y la tala ilegal. También podrían ser abogados, periodistas o personal de ONG, que trabajan para exponer el abuso ambiental y el acaparamiento de tierras. ${ }^{16}$

Así, la Declaración sobre Defensores establece en su artículo 1 que «toda persona tiene derecho, individual o colectivamente, a promover y procurar la protección y realización de los derechos humanos y las libertades fundamentales en los planos nacional e internacional». Por su parte, el artículo 9 reconoce que toda persona tiene derecho, individual y colectivo a -entre otras cosas-: denunciar las políticas y acciones de los funcionarios y órganos gubernamentales en relación con violaciones de los derechos humanos y las libertades fundamentales mediante peticiones $\mathrm{u}$ otros

16. «¿A qué precio?», Global Witness, 24 de julio de 2018, p. 12, disponible en https://bit.ly/3gFcLvM. 
medios adecuados ante las autoridades judiciales, administrativas o legislativas internas o ante cualquier otra autoridad competente prevista en el sistema jurídico del Estado, las cuales deben emitir su decisión sobre la denuncia sin demora indebida.

El derecho de los defensores a participar en actividades de protección y promoción de un medio ambiente sano ha sido reconocido por la Asamblea General de Naciones Unidas, desde 1982, en la Carta Mundial de la Naturaleza, la cual reconoce que toda persona «tendrá la oportunidad de participar, individual o colectivamente en la preparación de las decisiones que conciernen directamente a su medio ambiente, y cuando éste haya sido objeto de daño o deterioro, podrá ejercer los recursos necesarios para obtener una indemnización». Asimismo, en el ámbito internacional, el Programa Agenda 21 de la Conferencia de Naciones Unidas sobre el Medio Ambiente y el Desarrollo reconoció la importancia de la cooperación entre las organizaciones y los Estados para procurar la conservación del medio ambiente y lograr el desarrollo (Borras, 2019).

Por último, cabe destacar dos instrumentos internacionales, esto es, la "Convención sobre el acceso a la información, la participación del público en la toma de decisiones y el acceso a la justicia en asuntos ambientales» (Convención de Aarhus de 1998), y el «Acuerdo regional sobre el acceso a la información, la participación pública y el acceso a la justicia en asuntos ambientales en América Latina y el Caribe» (Acuerdo de Escazú de 2018).

La Convención de Aarhus, aunque de manera general, establece que las partes deberán conceder el reconocimiento y el apoyo requeridos a las asociaciones, organizaciones o grupos que tengan por objetivo la protección del medio ambiente y procurará que su sistema jurídico nacional sea compatible con esta obligación (artículo 3.4).

Por su parte, el Acuerdo de Escazú, aunque aún en espera de entrar en vigor, es el primer instrumento internacional en regular la situación de los defensores ambientales. En particular, en su artículo 9, establece disposiciones específicas para garantizar un entorno seguro y propicio para las labores de los defensores; reconocer, proteger y promover los derechos de los defensores de derechos humanos en asuntos ambientales; y dispone que Estados tomen medidas apropiadas, efectivas y oportunas para prevenir, investigar y sancionar ataques y amenazas, entre otros.

En lo que respecta a la protección de los defensores ambientales, como defensores de los derechos humanos que son, gozan de los beneficios que se establecen como derechos en los diferentes instrumentos de protección reconocidos a nivel internacional, entre los cuales se incluyen: el derecho a promover y luchar por la protección de los derechos humanos; el derecho a ser protegido; el derecho a la libertad de opinión, a libertad de expresión y a desarrollar y discutir nuevas ideas sobre los derechos humanos; el derecho a acceder y comunicarse con organizaciones internacionales, y a recibir financiación; el derecho a la libertad de reunión, a la libertad de asociación, a protestar y a acceder a recursos legales efectivos (Borras, 2019). 
Por su parte, la Resolución del 20 de marzo de 2019 del Consejo de Derechos Humanos de Naciones Unidas, relativa al «Reconocimiento de la contribución que hacen los defensores de los derechos humanos relacionados con el medio ambiente al disfrute de los derechos humanos, la protección del medio ambiente y el desarrollo sostenible», expresa «gran preocupación por la situación de los defensores de los derechos humanos relacionados con el medio ambiente en todo el mundo, y condena enérgicamente los asesinatos y todas las demás violaciones o vulneraciones de los derechos humanos» (párrafo 1), destacando además que «debe garantizarse a los defensores de los derechos humanos, incluidos los defensores de los derechos humanos relacionados con el medio ambiente, un entorno seguro y propicio que les permita llevar a cabo su labor sin obstáculos ni inseguridad» (párrafo 2).

Dificultades institucionales y legales que tienen que enfrentar los defensores en la región

En este apartado corresponde revisar las dificultades legales e institucionales que minan la actividad de los defensores ambientales. Entre ellas, podemos identificar tres grupos importantes de obstáculos.

\section{Control y restricción a las organizaciones no gubernamentales}

Los defensores ambientales comúnmente están asociados con alguna ONG o trabajan cercanos a una. La posibilidad de crear o unirse a una ONG es parte integral de la libertad de asociación que refuerza el trabajo de defensa del derecho humano a un medio ambiente sano. Las restricciones legales que se imponen a la formación o colaboración con ONG atentan contra la libertad de asociación, y están abiertamente en contra del artículo 5 de la Declaración sobre Defensores (Gleason y Mitchell, 2009). Estas leyes también restringen el derecho a la libertad de expresión, y el derecho a buscar apoyo financiero.

El año 2015, el Gobierno de Bolivia decidió reforzar los sistemas de control de las ONG que operan en el país argumentando que algunas no cumplen con un rol social y se dedican a conspirar contra el Gobierno central, ya sea financiando protestas antigubernamentales $\mathrm{o}$ asumiendo posturas abiertamente políticas. ${ }^{17}$

Por su parte, en Ecuador el año 2013 fue publicado el Decreto Presidencial 16, con el objetivo de controlar cualquier forma de organización social y prohibir las «actividades de política partidista, reservadas a los partidos y movimientos políticos [...] que atenten contra la seguridad interna o externa del Estado o que afecten la paz pú-

17. «Bolivia dice solo expulsará a ONG extranjeras si se entrometen en política», El Diario, 13 de agosto de 2015, disponible en https://bit.ly/3eaGLxY. 
blica». A partir de su aplicación, el Ministerio del Ambiente de Ecuador disolvió una ONG de defensa de los pueblos indígenas y derechos ambientales, con más de quince años de trayectoria, que se oponía a los proyectos petrolíferos del sur de la selva. Aunque dicho decreto fue derogado, hoy subsiste el Reglamento Sistema Unificado Información de Organizaciones Sociales de 2015, que contiene idéntica disposición para las ONG extranjeras (artículo 33).

\section{Tipos penales ambiguos e indeterminados en sentido general,} no concretamente ambiental

Los defensores que participan de manera activa, sea mediante protestas, manifestaciones $\mathrm{u}$ otras formas de incidencia, han sido acusados sobre la base de diversos tipos penales. El uso indebido del derecho penal para criminalizarlos puede caracterizarse por el uso abusivo de delitos frecuentemente definidos de forma contraria al principio de lex certa (ISHR, 2015). De esta manera, los defensores enfrentan la formulación por parte de los Estados de tipos penales indeterminados.

A lo largo de la región, se identifica la utilización arbitraria de tipos penales vagos o ambiguos para criminalizar o restringir el trabajo de los defensores ambientales. Entre dichos tipos penales se encuentran «ataques a las vías de comunicación y transporte», «atentado contra la riqueza nacional», o incluso haber «privado de libertad a alguna persona», entre otros.

En el caso de Guatemala, se amplió el delito de secuestro para incluir la privación de libertad de personas en el marco de tomas de edificios para exigir prestaciones o acciones al Estado (ISHR, 2015). A su vez, la Ley de Orden Público se ha invocado repetidamente para limitar en forma excesiva el derecho de reunión pacífica y reprimir la defensa de los derechos humanos en el contexto de las operaciones de empresas. Según la Unidad de Protección a Defensores y Defensoras Guatemala (UDEFEGUA), los estados de excepción se declaran arbitrariamente y en condiciones que caen fuera de las permitidos por el derecho internacional, lo que autoriza a la fuerza pública a irrumpir las reuniones, reprimir los movimientos sociales por la fuerza y de manera arbitraria detener a sus miembros sin una orden judicial (ISHR, 2015).

Por su parte, en Colombia, el delito de «obstrucción a vías públicas que afecten el orden público», creado por el artículo 44 de la Ley 1.453, de 2011, abre espacio para la judicialización de cualquier tipo de manifestación pacífica, por la ambigüedad de sus términos. Esta misma ley, que modificó el Código Penal, otorga penas de varios años de cárcel por actos como la "perturbación de actos oficiales» (artículo 15) y «perturbación en servicio de transporte público, colectivo u oficial» (artículo 45). Esta normativa crea obstáculos desproporcionados a las libertades de reunión y manifestación, al tiempo que posibilita la judicialización de los defensores ambientales, 
así como de la ciudadanía que se moviliza en forma pacífica en favor de la protección y el respeto a sus derechos.

Bolivia cuenta con la Ley 367 de 2013 contra los avasallamientos mineros, que penaliza con seis a ocho años de cárcel a quienes irrumpan en áreas mineras e impidan la explotación de los yacimientos (artículo 223 bis); por su parte, la nueva Ley de Minería y Metalurgia de 2014, en sus artículos 99 y 100, establece como delito las acciones individuales y colectivas que impidan la actividad minera.

En el caso del Perú, la regulación en el Código Penal del delito de «entorpecimiento al funcionamiento de servicios de transporte» tiene una pena mínima de prisión de cuatro años y máxima de ocho, y el delito de «disturbios» una pena mínima de seis y máxima de ocho años de prisión. Así, la conflictividad socioambiental en el Perú ha estado acompañada del aumento de las penas y ampliación de tipos penales para facilitar su acción punitiva contra defensores (ISHR, 2015).

Por último, respecto de los factores que contribuyen a la criminalización, es importante subrayar el rol del Poder Judicial y el Ministerio Público. Su falta de independencia y de imparcialidad tiene un impacto determinante en el fenómeno de la criminalización de defensores, en especial la actividad del Ministerio Público, que lidera la acción penal. Además de decidir criminalizar en forma indebida a un defensor, puede solicitar la prisión preventiva y en muchos casos se empeña en perseguir penalmente más de una vez a los mismos defensores, como ocurrió en los casos de Berta Cáceres, del cacique Babau, Saúl Méndez y Rogelio Velásquez (ISHR, 2015).

\section{Leyes antiterroristas}

La leyes y normas de seguridad nacional y antiterrorismo han sido utilizadas por los gobiernos para restringir el trabajo de defensores de derechos humanos. Muchas de estas leyes incluyen definiciones vagas que autorizan a las autoridades locales a arrestar o poner bajo detención a cualquier persona que esté en desacuerdo con el Estado, lo que acarrea además severas penas. Esto produce un efecto paralizante (chilling effect) en cualquier trabajo que implique expresiones legítimas de disensión, incluidas las que se oponen a las acciones que infrinjan el derecho humano a un medio ambiente limpio y saludable (Gleason y Mitchell, 2009).

El panel creado por la Comisión Internacional de Juristas (ICJ, 2009) detalló casos de varios países con definiciones vagas o demasiado amplias del concepto de terrorismo y actos terroristas, entre los que destaca el caso chileno. El contexto es una disputa histórica entre en Estado de Chile y el pueblo mapuche, que se ha ido acentuando desde el 2011 con la aplicación reiterada de la Ley 18.314 de 1984, que Determina Conductas Terroristas y Fija su Penalidad, a activistas mapuches. Dicha ley es cuestionada por permitir el establecimiento de condenas sobre la base de testigos cuya identidad es anónima (artículos 15 y 16), largos periodos de detención a espera 
de audiencia ante el tribunal (artículo 11) y la facultad de hasta duplicar las penas en una sentencia (artículos 3 y 3 bis). En esencia, se ha señalado que dicha legislación vulnera el debido proceso, posee una definición muy vaga del delito de terrorismo (artículos 1 y 2) y pone en peligro la integridad física y sicológica de los imputados, sobre todo defensores indígenas de su tierra y componentes ambientales sagrados en su cosmovisión.

Por su parte, en 2016 Brasil sancionó la Ley 13.260, llamada «ley antiterrorista», que estableció por primera vez este delito en el país. Contiene similares disposiciones que otras leyes antiterroristas, con cuestionamientos a los términos amplios en los que se refiere a actos terroristas (artículo 2) y las elevadas penas que dispone para ello, consistentes en privación de libertad por 12 a 30 años. Aunque el parágrafo 2 del artículo 2 dispone que no se aplicarán estas normas a «a la conducta individual o colectiva de personas en manifestaciones políticas, movimientos sociales, [...] dirigidos por propósitos sociales o reivindicatorios, con el fin de [...] defender derechos, garantías y libertades constitucionales», al final queda al arbitrio del juez determinar si los defensores de derechos humanos se encuadran en dicha conducta.

\section{Buenas prácticas}

Las obligaciones de los Estados sobre derechos humanos relacionados con el medio ambiente se pueden clasificar en tres principales categorías: obligaciones de procedimiento, sustantivas y de respecto de las personas que son parte de los grupos en situación vulnerable (Knox, 2017).

\section{Obligaciones y derechos procedimentales ambientales:}

El camino a la firma y ratificación del Acuerdo de Escazú

El saliente relator especial de derechos humanos, John Knox, ha enfatizado en reiteradas ocasiones cuáles son los requisitos claves que los Estados deben cumplir para establecer un ambiente seguro y que permita el trabajo de los defensores de derechos humanos, y uno de estos puntos esenciales son las obligaciones de procedimiento. En este sentido, para dar pie a una protección del ambiente sustantiva y eficaz, los Estados deben asegurar derechos básicos instrumentales o procedimentales, como derecho a la información, participación y justicia en asuntos ambientales.

En marzo de 2018, se adoptó el Acuerdo de Escazú, cuyo principal objetivo es garantizar la implementación plena y efectiva en América Latina y el Caribe de los derechos de acceso a la información ambiental, participación pública en los procesos de toma de decisiones ambientales y acceso a la justicia en asuntos ambientales. Se trata de un acuerdo vinculante que busca elevar los estándares con que hoy se resuelven los conflictos socioambientales en los territorios. Además, como ya se dijo, 
es el primero en el mundo en contener disposiciones específicas sobre defensores de derechos humanos en asuntos ambientales.

A la fecha, 22 de los 33 países de la región han firmado el Acuerdo ${ }^{18}$ lo que da cuenta cuenta de su compromiso en mejorar y reforzar sus marcos legales en la protección del ambiente y de los defensores que trabajan por ello. Aunque a la fecha ha sido ratificado por 9 países, aún falta que ratifiquen 11 Estados para entrar en vigor.

\section{Obligaciones sustantivas}

Los Estados tienen la obligación de adoptar marcos legales e institucionales que protejan frente a interferencias respecto del derecho de toda persona a vivir en un medio ambiente sano. Esta obligación no implica el cese de cualquier actividad que pueda causar degradación ambiental, pero sí regular su impacto. El análisis pormenorizado de las regulaciones sustantivas - de distintos cuerpos normativos de cada país- escapa al objeto de este estudio, pero cabe destacar que, del equilibrio que se logre, no pueden resultar violaciones graves a los derechos humanos (Knox, 2017).

\section{Obligaciones en asuntos ambientales: Países con leyes específicas destinadas} a la protección de los defensores de derechos humanos

Sin perjuicio de los desafíos expuestos a lo largo de este trabajo, no pueden soslayarse los esfuerzos de los países en construir marcos normativos que reconozcan y protejan de los riesgos que corren los defensores ambientales. Por ello, en la tabla 1 se detallan los países que cuentan con un cuerpo legal que define y adopta medidas de protección integral para los defensores de derechos humanos, que incluye a representantes de organizaciones sociales, étnicas, de mujeres y ambientales.

\section{Conclusiones y recomendaciones}

A lo largo del presente artículo, se revisó el vínculo entre un ambiente sano y los derechos humanos, con un análisis tanto de la construcción moral como legal, para concluir que el derecho a un ambiente sano ya es un derecho humano.

Luego, se detalló la regulación del ambiente sano en las distintas constituciones de América Latina y el Caribe, lo que evidenció un profuso desarrollo. Por otra parte, se analizó la regulación internacional que evidencia el vínculo entre un ambiente sano y los derechos humanos, lo que mostró su carácter autónomo, y cómo la Corte IDH en diferentes casos así lo ha entendido, a pesar de no ser un derecho contemplado en

18. El estado actualizado se encuentra en «Status of treaties: 18. Regional Agreement on Access to Information, Public Participation and Justice in Environmental Matters in Latin America and the Caribbean», United Nations Treaty Collection, disponible en https://bit.ly/2BU1lI2. 
Tabla 1. Países con leyes específicas destinadas a la protección de los defensores de derechos humanos

\begin{tabular}{|c|c|c|}
\hline País & Cuerpo que lo regula & isposiciones destacadas \\
\hline Brasil & $\begin{array}{l}\text { Política Nacional de Proteção aos Defenso- } \\
\text { res dos Direitos Humanos (PNPDDH), define } \\
\text { prazo para a elaboração do Plano Nacional } \\
\text { de Proteção aos Defensores dos Direitos } \\
\text { Humanos e dá outras providências (Decreto } \\
6.044 \text { ) }\end{array}$ & $\begin{array}{l}\text { - Reconocimiento de los defensores (anexo artículo 2). } \\
\text { Medidas para prevenir, investigar y sancionar ataques (artículo } 3 \text { ). } \\
\text { - Protección a defensores, que establece el objetivo de la protección, } \\
\text { caracteriza las violaciones a los derechos de los defensores, establece } \\
\text { directrices específicas para la protección de los defensores y responsabili- } \\
\text { dad de los autores de amenazas e intimidaciones (anexo artículo } 2 \S 1, \S \\
\text { 2; anexo artículos } 5 \text { y 6). } \\
\text { - Reconocimiento de defensores (artículo 1). } \\
\text { - Promoción de los derechos de los defensores y perspectiva de género } \\
\text { (artículos } 2 \text { y 5). } \\
\text { - Medidas de protección (artículo 3). }\end{array}$ \\
\hline \multirow{3}{*}{ Colombia } & $\begin{array}{l}\text { Programa Integral de Seguridad y Protec- } \\
\text { ción para Comunidades y Organizaciones } \\
\text { en los Territorios (Decreto } 1.066 \text { de 2015, } \\
\text { libro 2, parte 4, título 1, capítulo 7, Único } \\
\text { Reglamentario del Sector Administrativo } \\
\text { del Interior) }\end{array}$ & $\begin{array}{l}\text { - Reconocimientos de defensores y sus derechos (artículos 2.4.1.7.1.3 } \\
\text { y 2.4.1.7.1.9).- Protección y promoción de sus derechos, y enfoque de } \\
\text { género (artículos 2.4.1.7.1.2, 2.4.1.7.1.4, 2.4.1.7.1.7 y 2.4.1.7.2.8). } \\
\text { - Medidas para prevenir, investigar y sancionar ataques y amenazas; } \\
\text { entorno seguro y propicio; derecho a la participación; enfoque de género; } \\
\text { pueblos indígenas (artículos 2.4.1.7.1.7, 2.4.1.7.1.8, 2.4.1.7.2.1 y } \\
\text { 2.4.1.7.2.6). }\end{array}$ \\
\hline & $\begin{array}{l}\text { Decreto por el cual se organiza el Programa } \\
\text { Prevención y Protección de los derechos a la } \\
\text { vida, la libertad, la integridad y la seguridad } \\
\text { de personas, grupos y comunidades del Mi- } \\
\text { nisterio del Interior y de la Unidad Nacional } \\
\text { de Protección (Decreto 4.912) }\end{array}$ & $\begin{array}{l}\text { - Reconocimiento de los defensores (artículo 1). } \\
\text { - Protección y promoción de sus derechos (artículos } 3,4 \text { y 5).- Medidas } \\
\text { para prevenir, investigar y sancionar ataques } 0 \text { amenazas; entorno seguro } \\
\text { y propicio (artículos } 10,11 \text { y 12). }\end{array}$ \\
\hline & $\begin{array}{l}\text { Decreto por el cual se crea la Unidad } \\
\text { Nacional de Protección (UNP), se establecen } \\
\text { su objetivo y estructura (Decreto } 4.065 \text { de } \\
\text { 2011) }\end{array}$ & $\begin{array}{l}\text { - Reconocimiento de derechos de los defensores (artículo 3). } \\
\text { - Protección y promoción de sus derechos; entorno seguro y propicio } \\
\text { (artículo 4). }\end{array}$ \\
\hline Honduras & $\begin{array}{l}\text { Ley de protección para las y los defensores } \\
\text { de derechos humanos, periodistas, comu- } \\
\text { nicadores sociales y operadores de justicia } \\
\text { (Decreto 34-2015) }\end{array}$ & $\begin{array}{l}\text { - Reconocimiento de los defensores y sus derechos (artículos } 1 \text { y } 5 \text { ). } \\
\text { - Protección y promoción de sus derechos; derecho participación; derecho } \\
\text { recurrir (artículos } 4,6,8,9, \text { y } 10 \text { ). } \\
\text { - Medidas para prevenir, investigar y sancionar ataques } 0 \text { amenazas } \\
\text { (artículos } 11 \text { y 12). }\end{array}$ \\
\hline & $\begin{array}{l}\text { Ley para la Protección de Personas Defenso- } \\
\text { ras de Derechos Humanos y Periodistas }\end{array}$ & $\begin{array}{l}\text { - Reconocimiento de derechos de las personas defensoras (artículos 2, 4, } \\
8,9,17,24, \text { y 45). } \\
\text { - Medidas de prevención y protección (artículo 8, 16, 21, } 30 \text { y 45). } \\
\text { - Medidas para prevenir, investigar y sancionar ataques, amenazas o } \\
\text { intimidaciones (artículos 9, 16, 19,23, 26, } 32 \text { y 34). }\end{array}$ \\
\hline México & $\begin{array}{l}\text { Reglamento de la Ley para la Protección de } \\
\text { Personas Defensoras de Derechos Humanos } \\
\text { y Periodistas }\end{array}$ & $\begin{array}{l}\text { - Reconocimiento de derechos de los defensores (artículos } 2 \text { y } 3 \text { ). } \\
\text { - Entorno seguro y propicio (artículo 19). } \\
\text { - Protección y promoción de sus derechos (artículos 22, } 45 \text { y 52).- Me- } \\
\text { didas apropiadas, efectivas y oportunas para prevenir, investigar y } \\
\text { sancionar ataques, amenazas o intimidaciones (artículos 59,63, 64, 65, } \\
66,68,100,101,102,106 \text { y 108). }\end{array}$ \\
\hline
\end{tabular}

Fuente: Elaboración propia a partir de los contenidos disponibles en el Observatorio de Principio 10, disponible en https://observatoriop10.cepal.org/es. 
la CADH. Por último, se insistió en la importancia de contar con un instrumento internacional que consagre un ambiente sano como un derecho humano, sin perjuicio de que, de verse frustrado dicho objetivo, no le resta la categoría actual de derecho humano que ya cuenta.

En el capítulo tercero se analizó quiénes son los defensores ambientales, con un detalle de las definiciones de defensores de derechos humanos, así como además de una propuesta de definición propia de defensores ambientales a la luz de lo aportado por organismos internacionales y diversos autores que han tratado la materia. A continuación, se analizó el marco internacional de protección de defensores de derechos humanos. Además, se abordó casos emblemáticos de obstáculos legales en diferentes países de la región, que minan la labor de los defensores ambientales.

Finalmente, en el capítulo cuarto, se analizaron ciertas buenas prácticas adoptadas por los países de la región, en particular respecto de las obligaciones con los defensores de derechos humanos en asuntos ambientales, países con leyes específicas destinadas a la protección de los defensores de derechos humanos.

Urge entonces que los países de la región firmen y ratifiquen el Acuerdo de Escazú, pues entre sus muchos beneficios, ayuda a reafirmar que los defensores del medio ambiente están realmente defendiendo los derechos humanos. En este mismo sentido, se subraya la importancia de apoyar la adopción de un marco normativo general para el ambiente, como lo busca el Pacto Mundial por el Ambiente.

Cabe hacer notar que los Estados deben continuamente asegurarse de que sus leyes no criminalicen ni obstruyan el ejercicio de los derechos a la libertad de expresión, de asociación y de reunión a -entre otros- los defensores de derechos humanos. Además, la mayoría de los Estados aún deben hacer mayores esfuerzos para crear programas específicos de protección a defensores de derechos humanos que prevengan y adviertan en forma anticipada las amenazas o daños que pueden sufrir los defensores.

Por último, no puede dejar de enfatizarse la especial vulnerabilidad que enfrentan los pueblos indígenas y las mujeres, típicamente excluidos de la toma de decisiones ambientales, que asumen el liderazgo defendiendo sus tierras y territorio.

La larga lista de personas que han dado su vida protegiendo la tierra y el ambiente es un antecedente reprochable a los Estados que han fallado en su promoción y protección, pero también un recordatorio importante sobre cómo el daño a los defensores se despliega más allá de la afectación a la persona, a todos los que nos beneficiamos de sus esfuerzos para proteger el planeta.

\section{Referencias}

Aguilar Cavallo, Gonzalo (2016). «Las deficiencias de la fórmula "derecho a vivir en un medio ambiente libre de contaminación” en la Constitución chilena y algu- 
nas propuestas para su revisión». Estudios Constitucionales, 14 (2): 365-416. DOI: 10.4067/S0718-52002016000200012.

Borras, Susana (2019). La defensa de la vida y el medio ambiente: La situación de las personas defensoras del medio ambiente. Pamplona: Aranzadi.

Boyd, David R. (2018). «Catalyst for change: Evaluating forty years of experience in implementing the right to a healthy environment». En John H. Knox y Ramin Pejan (editores), The human right to a healthy environment (pp. 17-41). Nueva York: Cambridge University Press.

Cepal, Comisión Económica para América Latina y el Caribe, y Naciones Unidas (2018). Acceso a la información, la participación y la justicia en asuntos ambientales en América Latina y el Caribe: Hacia el logro de la Agenda 2030 para el Desarrollo Sostenible. Santiago: Cepal. Disponible en https://bit.ly/3iBuQMS.

GLEason, Jennifer y Elizabeth Mitchell (2009). "Will the confluence between human rights and the environment continue to flow? Threats to the rights of environmental defenders to collaborate and speak out». Oregon Review of International Law, 11 (267): 267-30o. Disponible en https://bit.ly/2W1hLDo.

ICJ, International Commission of Jurists (2009). Assessing damage, urging action: Report of the Eminent Jurists Panel on terrorism, counter-terrorism and human rights. Ginebra. Disponible en https://bit.ly/2ZOVolo.

ISHR, International Service for Human Rights (2015). El rol de las empresas y los Estados en las violaciones contra los defensores y las defensoras de los derechos de la tierra, el territorio y el ambiente. Ginebra, Nueva York. Disponible en https://bit. ly/2ZRoHkg.

Knox, John (2017). Defensores de derechos humanos: Una crisis global. Versoix: Universal Rights Group.

Rodríguez-Garavito, César (2018). «A human right to a healthy environment? Moral, legal, and empirical considerations». En John H. Knox y Ramin Pejan (editores), The human right to a healthy environment (pp. 155-168). Nueva York: Cambridge University Press.

\section{Sobre la autora}

María Francisca Aguilar Campos es abogada de la Corte Suprema de Chile. Diplomada en Derecho Ambiental «Instrumentos de Gestión Ambiental: Nuevas Tendencias», de la Facultad de Derecho de la Universidad de Chile, y licenciada en Ciencias Jurídicas y Sociales de la misma casa de estudios. Antes consultora en División de Desarrollo Sostenible y Asentamientos Humanos, Cepal, Naciones Unidas; y actualmente abogada de la Unidad Ambiental de la División Legal de la Dirección General de Aguas. Ayudante de la cátedra Clínica Jurídica Ambiental de la Universidad de Chile. Se correo electrónico es mfaguilar@ug.uchile.cl. 
El Anuario de Derechos Humanos es una publicación semestral de referencia y consulta en materia de derechos humanos y campos afines. Busca ser un espacio de discusión de los temas centrales en el ámbito nacional e internacional sobre derechos humanos. Es publicado desde 2005 por el Centro de Derechos Humanos de la Facultad de Derecho de la Universidad de Chile.

\author{
EDITORA \\ Claudia Iriarte Rivas \\ ciriarter@derecho.uchile.cl \\ SITIO WEB \\ anuariocdh.uchile.cl \\ CORREO ELECTRÓNICO \\ anuario-cdh@derecho.uchile.cl \\ LICENCIA DE ESTE ARTÍCULO \\ Creative Commons Atribución Compartir Igual 4.o Internacional
}

\author{
\% \\ La edición de textos, el diseño editorial \\ y la conversión a formatos electrónicos de este artículo \\ estuvieron a cargo de Tipográfica \\ (www.tipografica.io)
}

